San Jose State University

From the SelectedWorks of Bo Mou

2016

How the Validity of the Parallel Inference is Possible: From the Ancient Mohist Diagnose to a Modern Logical Treatment of Its SemanticSyntactic Structure

Bo Mou, San Jose State University 


\title{
How the Validity of the Parallel Inference is Possible: From the Ancient Mohist Diagnose to a Modern Logical Treatment of Its Semantic-Syntactic Structure
}

\author{
BO MOU \\ San Jose State University, USA \\ bo.mou@sjsu.edu
}

(2016/2/24 final version)

\begin{abstract}
The purpose of this paper is to explore the issue of how the validity of the parallel inference (as a type of deductive reasoning) is possible in view of its deep semantic-syntactic structure. I first present a philosophical interpretation of the ancient Mohist diagnose of the parallel inference concerning its semantic-syntactic structure. Then, to formally and accurately capture the later Mohist point in this connection for the sake of giving a general condition for the validity of the parallel inference, I suggest a modern logical treatment via an expanded predicate logic account.
\end{abstract}

In this paper, I explore the issue of how the validity of the parallel inference, as a type of deductive reasoning, is possible in view of its deep semantic-syntactic structure. My strategy is this: first, I will present a philosophical interpretation of the ancient Mohist diagnose of the parallel inference in the later Mohist text Xiao- $Q u$ concerning its semantic-syntactic structure; second, to formally and accurately capture the later Mohist point in this connection for the sake of giving a general condition for the validity of the parallel inference, I will suggest a modern logical treatment that is formally sensitive to the semantic-syntactic structure of the parallel inference and thus gives a general condition for its validity via an expanded predicate logic account.

In my following discussion, I start with identifying and characterizing the semantic-syntactic structure of the parallel inference (also labeled 'parallelism' or 'linguistic-parallel inference'), which the later Mohists" labeled "mou" (侔 mou) type inference and gave a reflectively interesting and engaging diagnose in the later Mohist text Xiao-Qu (《小取》Selecting the Lesser; 'the $X Q$ ' for short below) and its surrounding remarks in the Mo-Jing text (《墨經》). In so doing, I intend to provide a philosophical interpretation of the later Mohist diagnose of the parallel inference concerning the issues of how its validity is possible and of how the point in the later Mohist diagnose can contribute to an enhanced and enriched predicate logic account.

\footnotetext{
${ }^{1}$ The phrase 'the later Mohist' is used as a collective name referring to a group of anonymous members of the Mohist school during China's Warring States period (480-222 BCE) who are considered to author and compile the text, the Mohist Canons (a set of shorter or longer statements), which is also called the Mo-Jing (墨經) text [part of the $M o-Z i$ (墨子)] text (chapters 40-45) which focuses largely on logic thought and ideas in philosophy of language. The Mohist Canons consists of <1> "Jing-Shang" (經上 Canons A) and its explanations "Jing-Shuo-Shang" (經說 上 Explanations A), <2> “Jing-Xia” (經下 Canons B) and its explanations “Jing-Shuo-Xia” (經說下 Explanations B), <3> “Da-Qu” (大取 Selecting the Greater), and “Xiao-Qu” (小取 Selecting the Lesser).
} 
My views are these. (1) Essentially along with Gongsun Long's line in this connection, the later Mohist was highly sensitive to the refined semantic relation between language expressions and the way things are in the predicative context of saying something of what is designated; the later Mohists further implemented this semantic sensitivity in their reflective examination of the parallel type of deductive reasoning; such a semantic-truth concern in the later Mohist logical discourse motivated the later Mohist to alert us to meet certain adequate conditions for the sake of adequately carrying out the parallel inference. (2) On the other hand, the later Mohists then did not have sufficient or adequate logical resources to formulate the general inference rule for the validity of the parallel inference in an effective and unified way for the sake of guaranteeing its adequate applications (in the case of “是而然”, explicitly addressed, and of “不是而不然”, implicitly addressed) against introducing inadequate (i.e., contextually irrelevant) premises (in the cases of “是而不然” and “不是而然”); this has partially brought about, or at least contributed to the subsequent misunderstanding and mistreatment of the status and nature of the parallel inference. (3) However, with some enhanced predicate logic resources, the deep semantic-syntactic structure of the parallel inference can be captured and presented in a formal way, although both ancient logical resources during the later Mohist times and the so-faravailable logical resources (including those currently available expanded predicate logic accounts) have yet to be refined enough to take on, or are unable to formally apprehend, this.

A significant relevance of this discussion to a more general concern, to whose scholarship this discussion is also intended to contribute, is this. For the sake of giving a refined consideration of the validity of a deductive reasoning that involves saying something of an object (objects) under examination, the discussion in this article addresses the need for maintaining adequate semantic sensitivity to which aspect of the object(s) is in perspective focus in such a reasoning; this discussion suggests one way to treat the need via explicitly introducing an enhanced identity (symbol) with the "attribute-in-perspective-focus" parameter in an expanded predicate logical account, which might have some more general implication to the case of the parallel inference.

To explain and argue for the foregoing views, my strategy is this. In Part 1 , I will give a philosophical interpretation of the later Mohist diagnose of the validity of the parallel inference. In Part 2, I will discuss how the semantic-syntactic structure of the parallel inference can be effectively captured in terms of the resources in an enhanced predicate logic account, whose syntax and semantics are formally presented.

\section{An analysis of the later Mohist diagnose of the parallel inference}

In this section, I first give a preliminary interpretation of the later Mohist diagnose of the validity of the parallel inference and then explain the point of the later Mohist diagnose concerning the deep semantic-syntactic structure of the parallel inference.

\subsection{A preliminary interpretation of the later Mohist diagnose of the parallel inference}

The “Xiao-Qu” (小取 Selecting the Lesser; 'XQ' for short below), Chapter 45 of the Mo-Zi 《墨 子》 is one of the most important classical texts concerning logical thought and argumentation in the classical Chinese philosophy. It is relatively self-contained. In the following I focus on the relevant parts of the $X Q$ to the parallel inference, whose Chinese originals together with my English translation of those parts are given below [those within bracket parentheses are my own 
interpretative paraphrases]. ${ }^{2}$

In the opening passage, the $X Q$ gives a general characterization of disputation in view of its strategic and tactic goals:
夫辯者, 將以明是非之分, 審治亂之紀, 明司異之處, 察名實之理, 處利害, 決嫌疑。焉摹 略萬物之然, 論求群言之比。以名舉實, 以辭抒意, 以說出故, 以類取, 以類予。有諸已不 非諸人，無諸己不求諸人。或也者，不盡也。假者，今不然也。
Disputation/argumentation (辯) is to clearly distinguish between what is this/so and what is not- this/so [是非 right and wrong, true and false, or adequate and inadequate], examine the patterns of order and disorder, differentiate where sameness and difference are located, investigate the principles of names and objects, make judgment of what is beneficial and harmful, and resolve suspicion and doubts. Thereby one can depict and capture (摹略) the ways ten-thousand things are (萬物之然) and explore what distinguish various sayings. Names are used to designate objects; phrases are used to express ideas; explorations are used to bring out reasons. By virtue of kinds selections are made; by virtue of kinds inferences are drawn. If one maintains it in oneself, one should not criticize it in others [not addressing it in this negative way]; if one does not maintain it in oneself, one should not demand it of others [not addressing it in this demanding way]. Some-so is not exhaustive-so; supposed-so is currently not-so.

Among others, 焉摹略萬物之然(i.e., capturing the way things are) both highlights one strategic goal of reflective disputation/argumentation and provides one strategic standard as what is modeled on. The $X Q$ then gives the underlying rationale of a variety of argumentation via modeling:

效者，為之法也，所效者所以為之法也。故中效，則是也；不中效，則非也。此效也。

Modeling is to have something as a standard; what is modeled on is that by which a standard is set up. Therefore, if a thing matches a model, then it is so [right or true]; if it does not match the model, then it is not so [wrong or false]. This is what modeling is.

and four forms of argumentation under examination:

\footnotetext{
${ }^{2}$ Two notes are due. First, as different translations of the $X Q$ more or less present their translators' distinct interpretations, the interested readers might read my translation here in comparison and contrast to some other scholars' translations, such as that in Graham 1978/2003 and some recent English translations in Johnson 2000 and Robin 2010.

Second, in view of the purpose of this article, I focus only on the relevant parts of the $X Q$ to the parallel inference, instead of examining all its passages: in so saying, I mean that I will not examine the last two types of inference situations, i.e., the type of inference instances each of which a thing is general (in one case) [in premise] but is not general (in another case) [in conclusion] (一周而一不周) and the type of are instances in each of which a thing is so (in one case) [in premise] but is not so (in another case) [in conclusion] (一是而一非), not merely because there is no strong textual evidence for the $X Q$ author historically treating them also as instances of the parallel inference (it is noted that the $X Q$ also addresses other types of inferences respectively labeled '辟 $p i$ ', ‘援 yuan', and '推 tui'), but also (primarily) because these two types of inference instances do not fit the general scheme of parallel inference as well illustrated by these parallel-inference instances that the $X Q$ author classified into three types of situations [i.e., Situations (1), (2) and (3) to be labeled below]. As for how or to what extent the suggested strategy in treating the parallel inference can bear on the analyses of these two types of inference instances and how the parallel inference is related to the other three types of inferences addressed in the $X Q$, I will not explore these issues here for the sake of the major purpose of this article.
} 
辟也者，舉他物而以明之也。侔也者，比辭而俱行也。援也者，日「子然，我奚獨不可以然 也？」推也者，以其所不取之同於其所取者，予之也。是猶謂也者，同也。吾豈謂也[他]者異 也。

“Drawing an metaphor-analogy inference" (辟 $p i$ ) is making one thing clear by bringing up another similar thing; "Drawing a parallel inference" (佉 $\mathrm{mou}$ ) is comparing/contrasting [both] phrases [via identity or distinction regarding a certain aspect] and having both proceed in a parallel way [regarding the same aspect]; "Drawing a pulling-analogy inference" (援 yuan) is [what underlies] such sayings as "As you [the opponent in disputation] are so, why should I alone not be so?"; "Drawing a pushinganalogy inference" (推 tui) is drawing inference by recognizing what has not been selected to be the same as what has been selected. This amounts to saying that, if the other is the same, how can I say that the other is different?

The $X Q$ then makes some significant remarks on how to adequately employ the foregoing forms of argumentation via specific diagnoses and some general morals:

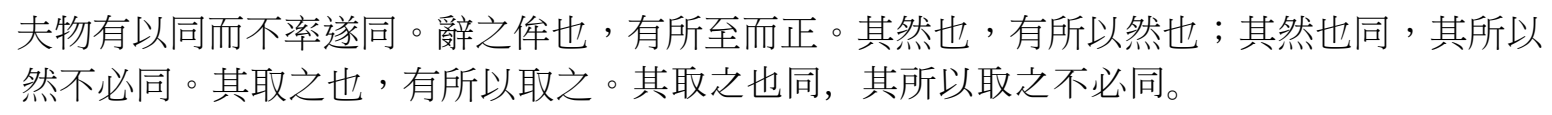

With things, there are aspects in which they are the same, but it does not follow that they are completely the same [they are different in some other aspects]. [This addresses one adequacy condition for adequately application of drawing a metaphor-analogy inference.] Drawing linguistic parallels of phrases is adequate when reaching/addressing due [identity] limit [due aspects of involved objects]. [This addresses one adequacy condition for adequately application of drawing a linguisticparallels inference.] When things are so, there are those by which they are so. They are the same in being so, but those by which they are so are not necessarily the same. [This addresses one adequacy condition for adequately application of drawing a pulling-analogy inference.] When things are selected, there are those by which they are selected. They are the same in being selected, but those by which they are selected are not necessarily the same. [This addresses one adequacy condition for adequately application of drawing a pushing-analogy inference.]

是故辟、佉、援、推之辭, 行而異, 轉而危, 遠而失, 流而離本, 則不可不審也, 不可常用 也。故言多方，殊類，異故，則不可偏觀也。

For this reason, argument by drawing [explicit] analogies, argument by "drawing linguistic parallels" [“佉”-style inference], argument by "pulling”, and argument by "pushing” go with their [respective] distinct limits as they proceed, can bring dangers as they turn around, result in failure as they go too far, and may leave their [respective] bases as they flow [without due control]. So one must carefully examine them [concerning their nature and adequate-application conditions] and avoid employing them in indiscriminate fixed ways without due sensitivity. Thus, linguistic discourses have multiple methods, involve distinct kinds, and resort to different reasons; they cannot be examined from the prejudiced point of view.

In the subsequent paragraphs, the $X Q$ focuses on the discussion of several representative applications of the parallel inference (i.e., “侔”-type inference) and makes its diagnose. Before presenting these paragraphs, let me first give a simple scheme of the parallel inference that can be presented in the following (not formally accurate but seemingly intuitive) way for the sake of rough illustration:

Case (1): 
$\begin{array}{ll}\text { Premise (or the primary premise): } & \mathrm{A}=\mathrm{B} \\ \text { [The additional Premise: } & S \mathrm{~A}] \\ \text { Conclusion: } & S \mathrm{~A}=S \mathrm{~B}\end{array}$

or

Case (2):

Premise (or the primary premise): $\quad \mathrm{A} \neq \mathrm{B}$

[The additional premise: $\quad S A]$

Conclusion: $\quad S A \neq S B$

where ' $\mathrm{A}$ ' and ' $\mathrm{B}$ ' are names, and ' $S$ ' is a explicitly-given predicate that expresses a certain (relational) attribute being ascribed to what a name refers to. It seems that one can make parallel inference from the general case concerning the same of two (collections of) objects, which is expressed by the identity of two referring names ' $A=B$ ' [in Case (1), or in Case (2) ' $A \neq B$ ' concerning the distinction of the two phrases, where ' $A$ ' and ' $B$ ' respectively stand for two (collections of) objects], to a certain specific case concerning the same specific attribute being ascribed to the two (collections of) objects, which is expressed by the identity of two subjectpredicate phrases ' $S \mathrm{~A}=S \mathrm{~B}$ ' [in Case (1), or in Case (2), ' $S \mathrm{~A} \neq S \mathrm{~B}$ ' concerning the distinction of the two subject-predicate phrases, where ' $S A$ ' and ' $S \mathrm{~B}$ ' respectively stand for two (collections of) objects possessing the same specific attribute that is expressed by an explicitly-given (relational) predicate].

Several notes are due. First, in the parallel inference, there is an implicit premise to assume that a specific (relational) attribute (expressed by the explicitly-given ' $S$ ') being ascribed to the object referred to by the referring name ' $A$ ' on the left-hand side of the identity symbol [in Case (1), or on the left-hand side of the non-identity symbol in Case (2)]. Second, the parallel inference is not an analogical guesswork concerning a specific case inferred from another specific case; rather, it is a kind of deductive inference from the general case concerning the identity or distinction of two (collections of) objects to the entailed specific case concerning the identity or distinction of the two (collections of) objects (assumingly) having a certain specific attribute (including the adequate premise of a parallel inference "entailing" the same aspect with which the conclusion is concerned, a crucial point to be explained below), although a parallel appearance has sometimes led ("misled", to be explained below) people to identify the parallel inference as one type of analogical inference. ${ }^{3}$ Third, it is more or less inaccurate and misleading

\footnotetext{
${ }^{3}$ In the literature on the issue of the status and nature of the parallel inference, it is controversial whether the parallel inference is a type of deductive reasoning or a kind of analogical reasoning. Those scholars such as Graham 1967, Liu 2004, and Fung 2012 explicitly render it deductive: though Graham does not explain why he thinks so, while Liu and Fung give their essentially the same reason by formally presenting the parallel inference in terms of the standard first-order predicate logic resources. In contrast, some other scholars such as Hansen 1983 and Fraser 2013 render it analogical. On this issue, I agree to the former's position, while disagreeing to the latter. However, as the reader will see, my reason for rendering the parallel inference deductive is substantially different from that as presented in Liu 2004 and Fung 2012. It is noted that the analogical inference is substantially weaker than the deductive reason in the sense that it cannot guarantee the strong entailment relationship between its premise(s) and its conclusion. It is arguably correct that the later Mohist diagnose is much more reflectively and logically engaging and significant when it examines the issue of how applications of the parallel inference can adequately maintain due semantic sensitivity and its related issue of the general validity of the parallel inference.
} 
to use the traditional identity symbol ' $=$ ' here as it is associated with reflexivity in the standard predicate logic resources: however, it is known that identity is a kind of predication; given that, semantically, predication is (or belong in) essentially what is said of the subject instead of the reverse, generally speaking, reflexivity should not be, and is not, one intrinsic attribute of predication, and thus, generally speaking, reflexivity should not be one intrinsic attribute of the identity as addressed here (tentatively labeled ' ${ }^{*}$ ' at this moment) whose more accurate formal characterization will be given in section 2.1 below, though it can be one attribute of the so-called "absolute" identity [i.e., what the term $\alpha$ denotes is identical to what the term $\beta$ denotes regarding ALL (universal) attributes]. In this way, there is the significance difference between $A=* B$ and $\mathrm{B}=* \mathrm{~A}$ and between $S \mathrm{~A}=* S \mathrm{~B}$ and $S \mathrm{~B}=* S \mathrm{~A}$.

Now, in the $X Q$, the later Mohists explicitly examined three distinct types of situations concerning various applications of the parallel inference, with concrete examples as illustrations: (1) the "shi-er-ran 是而然” situation where a thing is this [in premise] and thus is so [in conclusion]; (2) the “shi-er-bu-ran 是而不然” situation where a thing is this [in premise] but is not so [in conclusion]; (3) the “bu-shi-er-ran 不是而然” situation where a thing is not this [in premise] but is so [in conclusion]. Many applications of the parallel inference seem to be valid, while others not. They can be further classified into two kinds of situations, i.e., the first kind of the applications are considered to be adequate applications for the sake of valid parallel-type deductive reasoning, which consists of the explicitly-given Situation (1) of “shi-er-ran 是而然” where a thing is this [in premise] and thus is so [in conclusion] and implicitly-addressed Situation (1)* of “bu-shi-er-bu-ran 不是而不然” where a thing is not this [in premise] and thus is not so [in conclusion]". Both are considered to be adequate applications of the parallel inference. The later Mohists gave examples and illustrations of adequate applications of Situation (1) as follows:

\section{白馬，馬也；乘白馬，乘馬也。驪馬，馬也；乘驪馬，乘馬也。獲，人也；愛獲，愛人也。 㶓, 人也; 愛㶓, 愛人也。此乃是而然者也。}

The white horse is the horse; [therefore] riding the white horse is riding the horse. The black horse is the horse; [therefore] riding the black horse is riding the horse. Huo [the name of a female servant] is a person; [therefore] caring for Huo is caring for a person. Zang [the name of a male servant] is a person; [therefore] caring for Zang is caring for a person. There are instances in each of which a thing is this and thus is so (是而然).

Furthermore, the later Mohists identified and addressed the other kind of inadequate applications of the parallel inference which do not appear to be valid, that is, Situation (2) of "shi-er-bu-ran 是而不然” where a thing is this [in premise] but is not so [in conclusion] and Situation (3) of the “bu-shi-er-ran 不是而然” situation where a thing is not this [in premise] but is so [in conclusion]. Some examples and illustrations of Situation (2) are given as follows:

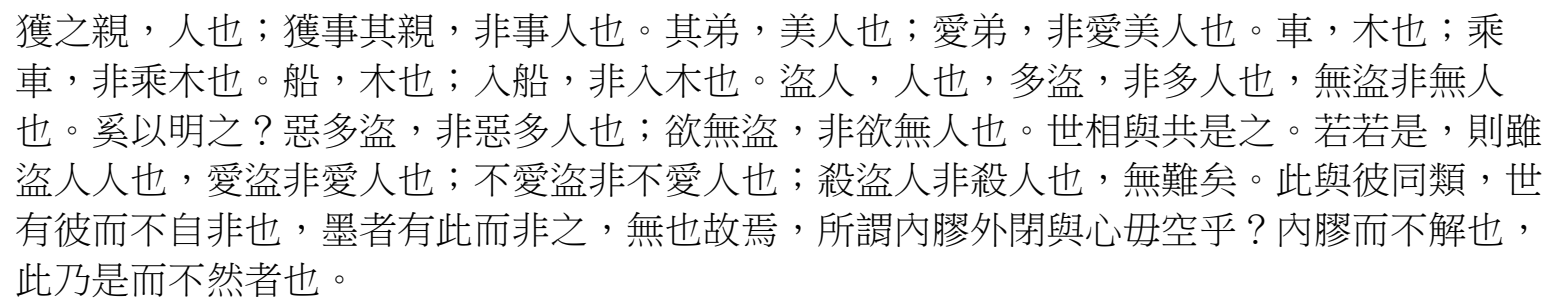

Huo's parents are persons; [but] Huo's serving her parents is not serving person. Her younger brother 
is a handsome person; [but] loving her younger brother is not loving a handsome person. The cart is wood; [but] riding the cart is not riding wood. The boat is wood; [but] entering the boat is not entering wood. The robber is the person; [but] many robbers are not many persons; there being no robbers is not there being no persons. How to make clear this? Hating there being many robbers is not hating there being many persons; desiring there to be no robbers is not desiring there to be no persons. There is the agreement in the world that this is so. If it is so, then, there is no difficulty with holding that, although the robber is the person [the former/the [inadequate] premise of this type of applications], caring for the robber is not caring for the person, not caring for the robber is not not caring for the person, and killing the robber is not killing the person [the latter/the conclusion of this type of applications]. The latter [此 $c i$ /the conclusion] and former [彼 $b i /$ the [inadequate] premise] are of the same kind [but with their distinct focuses on distinct aspects]; the ordinary people hold the former and do not consider themselves mistaken; however, they consider it mistaken for the Mohists to [also] hold the latter. This attitude is not reasonable and amounts to what is called "ossified inside and closed off outside, which results from the closed mind that is ossified inside without being susceptible to change”. These are instances in each of which a thing is this but is not so (是而不然).

Some examples and illustrations of Situation (3) are given as follows:

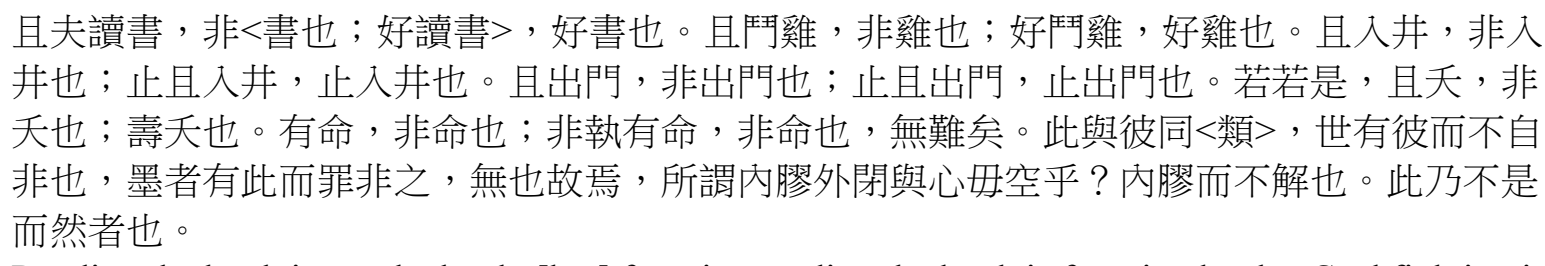

Reading the book is not the book; [but] favoring reading the book is favoring books. Cockfighting is not the cock; [but] favoring cockfighting is favoring the cock. Being about to fall into the well is not falling into the well; [but] stopping being about to fall into the well is stopping falling into the well. Being about to go out of the door is not going out of the door; [but] stopping being about to go out of the door is stopping going out of the door. If it is so, then, there is no difficulty with holding that: Being about to die young is not die young; [being about to die young but actually longevity is not dying young?] Claiming that there is the fate is not the fate; [but] rejecting claiming that there is the fate is rejecting the fate. The latter [此 $c i /$ the conclusion of this type of applications] and former [彼 $b i /$ the [inadequate] premise of this type of applications] are of the same kind [but with their distinct focuses on distinct aspects]; the ordinary people hold the former and do not consider themselves mistaken; however, they consider it mistaken for the Mohists to [also] hold the latter. This attitude is not reasonable and amounts to what is called "ossified inside and closed off outside, which results from the closed mind that is ossified inside without being susceptible to change". These are instances in each of which a thing is not this but is so (不是而然).

Though it is known that Situations (1) and (1)* are rendered adequate applications of the parallel inference while Situations (2) and (3) problematic, what are at issue are these: Why do (2) and (3) go wrong? Can we say that those application instances of the parallel inference in Situations (2) and (3) constitute genuine counter-examples to the generality of the parallel inference and thus show the failure of the parallel inference per se and, more generally speaking, deductive reasoning in this connection? What is the point of the later Mohist diagnoses here?

Some scholars think that Situations (2) and (3) show the failure of the parallel inference per se, if it is treated as a type of deductive reasoning, and, more generally speaking, any deductive 
reasoning in the connection of the parallel inference. ${ }^{4}$ One representative view is this: Situations (2) and (3) are treated as two modes of the parallel inference; the later Mohists realized and identified the problem with (2) and (3) and thus rendered some modes of the parallel inference invalid. One substantial implication of this interpretation, whether or not its advocates realize, would be this: therefore, the later Mohist rendered the parallel inference as a whole invalid because some modes of the parallel inference are invalid. ${ }^{5}$ Indeed, even those scholars who render the parallel inference deductive but who understand and present it in terms of the traditional or standard first-order predicate logic resources would face one serious difficulty with implicitly damaging the general validity and thus the deductive status of the parallel inference. It is arguably right to say that they thus have yet to adequately explain why (2) and (3) go wrong and what is the genuine point of the later Mohist diagnose. Let me explain why.

For those scholars who render the parallel inference deductive but who understand and present it in terms of the traditional or standard first-order predicate logic resources typically treat the (valid) allocations of Situation (1) as illustrations of the paradigmatic case of the parallel inference which needs to be formally presented in terms of the standard predicate logic resources in this way (for the sample inference from the sentence 'The white horse is the horse' to the sentence 'Riding the white horse is riding the horse'):

$$
\begin{aligned}
& \text { Premise: } \forall \mathrm{x}(S \mathrm{x} \rightarrow P \mathrm{x}) \\
& \therefore \forall \mathrm{x}((M \mathrm{x} \rightarrow \exists \mathrm{y}(S \mathrm{y} \wedge R \mathrm{xy})) \rightarrow(M \mathrm{x} \rightarrow \exists \mathrm{y}(P \mathrm{y} \wedge R \mathrm{xy})))
\end{aligned}
$$

Where ' $S$ ', ' $P$ ', and ' $M$ ' are respectively one-place predicates "is a white horse", "is a horse" and "is a person", ' $R$ ' is a two-place predicate "ride". ${ }^{6}$ One major difficulty with such an interpretation together with such a formal presentation of the parallel inference in terms of the currently standard predicate logic sources is this: this interpretation together with such a formal presentation would (at least implicitly) damage the deductive status of the parallel inference. Indeed, the original intention of this first-order predicate logic presentation is to explain the deductive-reasoning status and nature of the parallel inference in an accurate way; however, due to the limitation of the traditional first-order predicate logic resources, the result is quite opposite: once the parallel inference is turned into such formulation, it simply cannot go through Situations (2) and (3). Some authors consider such cases to be "anomalies" of the parallel inference due to the involved key terms being "either semantically ambiguous or pragmatically deviated"7 [i.e., such key terms are those predicates that express the (relational) attributes ascribed to the (collections of) objects, such as ' $R$ ' ("ride") above]; however, one difficulty with such a treatment would be this: if whether the validity of a type of the inference would be affected or even determined by the semantic ambiguity or pragmatic deviation of its key terms

\footnotetext{
${ }^{4}$ I think that those scholars (for example, Hansen 1983 and his followers on this issue) who render the parallel inference analogical (at least implicitly) essentially hold this view. This seems to be one consideration for them to interpret the later Mohist version of parallel inference as a kind of analogical reasoning.

${ }^{5}$ See Liu 2004, 83-88.

${ }^{6}$ For example, Liu 2004, 85, and Fung 2012, 342, giving (R). Also see Willman 2010, 65-66 (though using the sample inference from the sentence "Robbers are people" to the sentence "Killing robbers is killing people" in discussing some other issue in Mohism).

${ }^{7}$ Cf., Fung 2012, 342-343.
} 
instead of its form (or its formal structure) only, this type of inference would not have the rule for its general validity and thus is not entitled to be called a type of deductive inference. To this extent, this treatment, formally speaking and substantially speaking, would implicitly damage the the deductive status of the parallel inference and, I content, has yet to capture the genuine semantic-syntactic structure of the parallel inference to which the later Mohist diagnose pointed.

One might object this way: the invalidity of such an inadequate application of the parallel inference as presented in Situations (2) and (3) can be explained by the fact that the involved adding terms are ambiguous; for example, in the parallel inference "The robber is a person, killing a robber is not killing a person.", the two token of "sha" 殺 (killing) are ambiguous: the first one is "[killing by] execution" while the second one is "[killing by] murder"; for the same reason, the two tokens of 'cheng' 乘 (riding) in "The cart is wood; [but] riding the cart is not riding wood." are also ambiguous. The first one is "riding [in terms of taking vehicle]" while the second one is "straddle"; in this way their formulation should be different: if the first one is " $R_{1}$ ", the second one should be " $R_{2}$ "; there is thus no real difficulty with such an "ambiguity" interpretation. ${ }^{8}$ However, this objection has yet to capture the involved points of the foregoing analysis of the "ambiguity" interpretation in three connections or for three considerations. First, what is really at issue is not whether or not such ambiguous meanings per se can be formally presented in distinct ways but, as explicitly indicated above, why these inadequate applications of the parallel inference in Situations (2) and (3) go wrong from the point of view of logical inference (that is, from the point of view of addressing the inference's formal structure only with the rule for its general validity). I think that the "ambiguity" interpretation has yet to identify the real or primary source of the "invalidity" problem with such inadequate applications through its focusing on the involved ambiguity: yes, such ambiguity involved in the added terms is a linguistic fact, and yes, the addressed ambiguous meanings per se can be respectively presented in distinct formal ways; however, what is really at issue is why these inadequate applications of the parallel inference in Situations (2) and (3) go wrong from the point of view of logical inference. Second, the addressed ambiguity is only a derivative linguistic fact rather than the primary source for the invalidity of such inadequate applications of the parallel inference as presented in Situations (2) and (3): yes, there are two distinct meanings of the two tokens of the term 'riding' (or 'killing'); however, in the context of one specific case of parallel inference, exactly which meaning is focused on is to be determined by which aspect of the referent of $\mathrm{A}$ in the (primary) premise is to be focused on in this inference context; in the Mohist presentation of Situations (2) and (3), such inference contexts are explicitly given: given that such an inadequate application of the parallel inference is invalid, and given the truth of the conclusion statement with its given perspective focus (on a certain aspect of the referent of A) in such an inadequate application, the real or primary (instead of derivative) problem with it lies in its (primary) premise: what is at issue is not whether the primary-premise statement in isolation is true or false, but whether or not the (implicitly) addressed perspective focus (on one aspect of the subject, i.e., the referent of the the subject expression A under examination) in the premise statement is really relevant or irrelevant (or consistently related) to the perspective focus (on the addressed aspect of the referent of A) in the conclusion statement in view of the whole context of such an application of the parallel inference and for the sake of being a valid deductive inference; it is clear that distinct perspective focuses in the premise statements would result in bringing in distinct

\footnotetext{
${ }^{8}$ The version of the foregoing objection is cited from one anonymous referee's review report, which is interesting and provides me with an opportunity of further elaborating the relevant points of the suggested interpretation.
} 
meanings of such an added (relational) predicate that are to be closely or even intrinsically related to the distinct perspective focuses, ${ }^{9}$ but only one of them is relevant (or can be consistently maintained in such a specific inference context); now, for the sake of being a valid deductive inference, an adequate application of the parallel inference (as one type of deductive inference) needs to maintain the minimal consistency in this connection: an adequate application of the parallel inference not merely needs to consistently talk about the same objects respectively denoted by the same linguistic expressions in the premise and conclusion statements but also needs to consistently focus on the same aspect of the referents of subject expressions in the premise and the conclusion; otherwise the law of identity would be violated; consequently, the application of the parallel inference would be invalid, and the application of the parallel inference is thus inadequate. Third, given the two interpretations, another evaluation connection lies in which interpretation would have more explanatory force from the point of view of deductive reasoning: related to the above second point, the current interpretation captures the primary source of the invalidity of these inadequate applications of the parallel inference in Situations (2) and (3), instead of identifying the derivative ambiguity as the primary source, and thus arguably has more explanatory force in this connection; also the suggested interpretation can further reveal the genuine deductive-reasoning status of the parallel inference in view of the aforementioned approach that intends to characterize the parallel inference in terms of analogical inference, thus giving further justification for the broader direction of all those scholars who emphasize the deductive-reasoning nature of the parallel inference.

\subsection{The point of the later Mohist diagnose: semantic-sensitivity of the parallel inference}

Indeed, the later Mohists did not use these formal and conceptual resources that are directly or indirectly available to us now; however, based on their philosophically interesting and engaging analysis of the issue of identity and distinction both in the $X Q$ and generally speaking in the later Mohist Canons, essentially the same thought resources were already presented in their texts.

Based on the foregoing interpretative examination of the later Mohist diagnose, I think that one central point of the diagnose as presented in the $X Q$ is this: generally speaking, the later Mohists maintained due semantic sensitivity to the refined semantic relation between language expressions and the way things are in the predicative context of saying something about objects as referents of names; specifically speaking, the later Mohists implemented this semantic sensitivity in their reflective examination of the parallel inference: such a semantic-sensitivity concern motivated the later Mohists to alert us to meet certain adequate conditions for validly carrying out the parallel inference. What fails in (2) and (3) is not the parallel-inference deductive reasoning per se but its inadequate applications in (2) and (3); this indeed also shows the powerlessness of the logic resources in the ancient times (even those resources in the current market) to capture the deep semantic-syntactic structure of the parallel-inference deductive reasoning. In other words, the genuine point of the later Mohist diagnoses of (2) and (3) lies in this: the later Mohist diagnose aims at alerting us to have due semantic sensitivity to which

\footnotetext{
${ }^{9}$ For example, if the human-being aspect shared by the robber and the person is focused on, it would be closely related to the "killing by murder" meaning of the term 'sha' 殺 (killing); however, if the robber-criminal aspect possessed by the robber only (but not shared by ANY member of the person collection) is focused on, it would be closely related to the "killing by execution" meaning of the term 'sha' 殺 (killing). The conclusion statement in a specific application case of the parallel inference can (explicitly or implicitly) show which aspect is focused on (given the conclusion statement is true).
} 
aspect of the object under examination is focused on when carrying out the parallel inference and thus introducing and maintaining the genuinely relevant premise (with a due perspective focus) in an adequate application of the parallel inference. ${ }^{10}$

Indeed, the later Mohists then did not have due resources to formulate the general inference rule for the validity of the parallel inference in an effective and unified way for the sake of guaranteeing its adequate applications (in the case of “是而然”, explicitly addressed, and of “不 是而不然”, implicitly addressed) while against introducing inadequate (i.e., contextually irrelevant) premises (in the cases of “是而不然” and “不是而然”); this has partially brought about, or at least contributed to the subsequent misunderstanding and mistreatment of the status and nature of the parallel inference. Such a historical limitation of the later Mohists in this connection is not alone. The standard predicate logic with standard form of identity does not have sufficient logical resources to formally present the foregoing point of the later Mohist critical examination of various types of application situations of the parallel-inference deductive reasoning. However, this does not mean that there is any problem with the parallel-inference deductive reasoning per se but only shows that the standard predicate logic (with identity) has yet to have sufficiently powerful, adequate and sensitive logical resources to formally capture the deductive reasoning in this connection.

It is noted that, in view of the principle of charity in philosophical interpretation, and with the due assumption of the consistency of the later Mohist texts within the Mohist Canons, one can further identify the foregoing point of the later Mohist semantic sensitivity from some other major texts of the Mohist Canons. Let me consider some crucial passages in the "Jing-Shang" (經說 “Canons A”) \& the “Jing-Shuo-Shang” (經說上 “Explanations A”) [my translations: those paraphrase remarks within bracket parentheses and the point numbers are mine]:

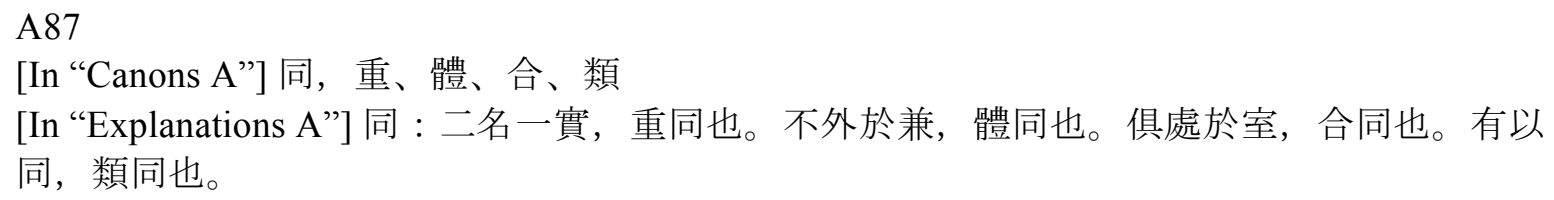

\footnotetext{
${ }^{10}$ It is noted that, in this fundamental connection, I contend that the later Mohists in their diagnose of the parallel inference and Gongsun Long's rationale in treating the "White-Horse-Not-Horse" thesis are essentially the same: any identity expression without being sensitive to which aspect is in focus would be semantically incomplete. This idea, logically speaking, is also labeled 'relative identify', which is often attributed to Geach 1967 in which Geach criticizes the standard notion of absolute identity in the standard first-order predicate logic (also see Deutsch 2007). For the reason explained here and in Mou 2007, in my view, the basic idea of relative identity as a kind of semantic sensitivity is a quite pre-theoretic natural and its first quite explicit presentation can be traced back to Gongsun Long (relative to what is sought, one can say that the white horse is identical to the horse or that the white horse is not identical to the horse, a fundamental point of Gongsun Long which I have explained in Mou 2007). As for its explicit logical presentation (in predicate logic resources), see footnotes 14 and 17.

With consideration that I have already given a detailed explanation of the "double-reference" character and the aforementioned "relative identity" point (though I then din not use the very phrase 'relative identity') of Gongsun Long's argumentation line for the "White-Horse-Not-Horse' thesis in Mou 2007, to save space and considering the major focus of this article, I will not say more on this in this article.

In view of this shared fundamental insight concerning such semantic sensitivity by Gongsun Long's line and the later Mohist line, in the following illustration of how the later Mohist semantic sensitivity to due aspects of involved objects can contribute to our understanding and treatment of the deep semantic-syntactic structure of the "parallelinference" type deductive reasoning, I intentionally use sample illustrations concerning the well-known "whitehorse-is-horse" case versus the "white-horse-is-not-horse" case.
} 
Tong (同 the same) [includes the following seemingly different but partially overlapping classification of the same things]: $<1>$ being duplicated; $<2>$ being parts; $<3>$ being together/united; $<4>$ being of a kind.

Tong (同 the same): $<1>$ What two names designate being one (identical) object is the same of being duplicated [the referential sameness]; $<2>$ [Both] Not being outside the whole is the same of being parts [the sameness of belonging to the one whole]; $<3>$ Both residing in one [single] place is the same of being together [the sameness of being united in one single thing]; $<4>$ Both being the same in some aspect is the same of being a kind [the sameness in regard to some aspect, i.e., the sameness of a kind].

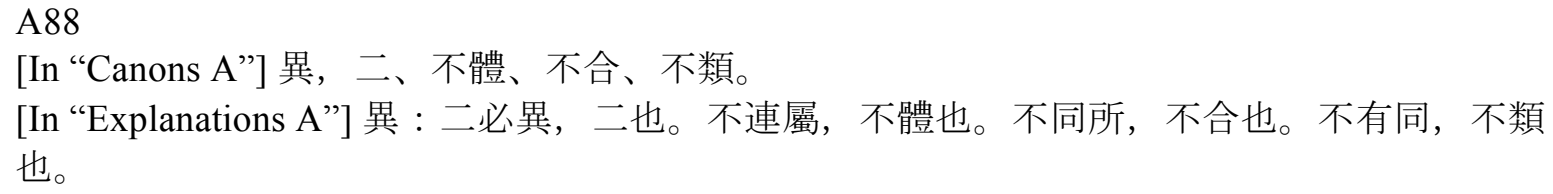

$Y i$ (異 different/distinct) [includes the following seemingly different but not mutually exclusive modes of the same things]: $<1>$ two [instead of being duplicated]; $<2>$ not being parts; $<3>$ not being together/united; $<4>$ not being of a kind.

$Y i$ (異 different/distinct): $<1>$ Two certainly different is two [the referential difference]; $<2>$ Not being jointed is not being parts [the difference of not belonging to the one whole]; $<3>$ Not residing in one [single] place is not being together [the difference of not being united in one single thing]; $<4>$ Not having the same [in some aspect] is not being of a kind [in regard to some aspect] [the difference in regard to some aspect, i.e., difference of a kind].

Analyzing the $X Q$ text together with examining the point of the relevant passages such as these passages cited above from the later Mohist Canons, one can identify several relevant points of the later Mohist logical discourse to their diagnose concerning the semantic-syntactic structure of the parallel inference. First, the last mode of the sameness as addressed in A87 is the most general one and can include the other modes as its sub-modes; in other words, the other modes can be viewed as special cases of the sameness of a kind: $<1>$ the referential sameness is the sameness of being of a class in regard to two names' having the same referent; $<2>$ the sameness of belonging to the one whole is the sameness of being of a class in regard to both having the same part-ship of the one whole $<$ both contributing to the identity of the one whole $>$, and $<3>$ the same of being unified in one single thing is the sameness of being of a class in regard to both being united by the same single thing (both contributing to the identity of the single thing). Similarly, as shown in A88, the difference of a kind can include the other modes of difference.

Second, what determines the identity of a kind? There seem two contributing elements: $<1>$ the objective "the way-things-are" foundation: there is some aspect that constitutes a "common" attribute $^{11}$ among the members of a collection kind; $<2>$ the aspect is what one (or a group of persons) focuses on and intends to capture for a certain purpose, which results in a certain

\footnotetext{
${ }^{11}$ It is important to note that the saying "common attribute" here does not necessarily commit itself to a platonic realism regarding universals but is open to distinct ontological interpretations. In Section 2.1 below when an expanded predicate logic account is given, such a "common" universal attribute is defined as the membership of a distinct subset of particular attributes [see $(2.1)<2.1>$ ]; the "membership" identity of a universal is open to distinct ontological interpretations, though one quite (or most) natural interpretation is conceptualism regarding universals in this context.
} 
(eligible) perspective that is intended to point to and capture the aspect. So to speak, the foregoing "the way-things-are" contributing element and "perspective" element would jointly determine the (adequate) identity of a collection kind and thus the identity standard; the former provides the "objective" foundation for the adequacy of the "shi/fei" criterion, while the latter is sensitive to our diverse purposes, interests and focuses in capturing the way things in the world are.

Third, different perspectives can result in distinct identities of kinds of involved things, but distinct identities of kinds are not necessarily incoherent. For example, when one focuses on (one of) those common-attribute aspects between the robber and the person [thus taking a (finite but eligible) perspective], one states that the robber is the same as the person [with regard to (one of) those common aspects] and thus sincerely takes it that they are of the same kind; to this extent (with the focus on the common aspect), one would say that killing the robber is the same as killing the person. On the other hand, when one (maybe the same one person) focuses on some distinct aspect(s) that is(are) not shared by the robber and the person (the person meaning any member of the person as a collection) [thus taking a distinct (finite but eligible) perspective], then one states that the robber is not the same as the person [with regard to that distinct aspect] and thus sincerely takes it that they are not of the same kind with regard to that distinct aspect; to this extent (with the focus on the distinct aspect), one would say that killing the robber is not the same as killing the person. It is noted that there is no contradiction here; there is no violation of the principle of non-contradiction both at the ontological level and at the level of linguistic expression: one object can possess all these distinct aspects at the same time; the foregoing distinct perspectives can be consistently taken by the same agent (as well as by different agents); thus the foregoing distinct cases point to a perspective shift in the agent. ${ }^{12}$

With such an adequate methodological guiding principle as one strategic vision, the Mohist approach realizes, recognizes and honors the adequacy and value of such perspective shift in reasoning. So to speak, in the above sense and to such extent, the foregoing interpretation of the Mohist approach might as well be called a "vision-guided perspective-shift" interpretation of the logical thought as concisely presented in the "Xiao-Qu" chapter of the Mo-Zi. In the next section, this "vision-guided perspective-shift" interpretation is more formally and accurately presented in terms of an expanded predicate-logic resources including an enhanced identity sign (the "identity" symbol with "perspective-attribute-in-focus" parameter).

One might have such a kind of doubt: it seems that such an interpretative treatment with an enhanced identity can be applied to any terms; if we add the expression "regarding some attribute that they share" in the parallel inference, all arguments of the same form can be accepted as valid, including those in situations (2) and (3); but why the Later Mohists treat them as invalid? My replies are "yes" and "no". It is an open-minded but the-way-things-are-capturing

\footnotetext{
${ }^{12}$ The basic point of this interpretation line on the reasoning patterns in the later Mohist logical discourse has been explained in Mou 2006 and Mou 2009). Indeed, there is one substantial implication of such understanding of identity (as labeled 'relative identity' in contemporary logic discourse, see the previous footnote 8): as one might object, it is thus possible that all different things in the world, in some sense, can be regarded as the same [or similar] from a relevant perspective. I would render such possibilities (or even some related "seemingly-bizarre" but really openminded ways of classification) very positive and constructive; this would give a thoroughly open-minded approach to look at identities/similarities among things in the world and at how to classify them: this would be sensitive to people's eligible perspectives that point to certain aspects which are really commonly possessed by things and thus meet certain reflective needs, though some of these classifications are trivial or against people's current ready-made or habitual ways of classification.
} 
"yes": given that any two things (collections of things) of all things in the world do possess a certain shared aspect and thus can be rendered "same" with regard to that aspect share by them, one can carry out a valid parallel inference concerning them, given that the aforementioned consistency regarding the same perspective focus on the aspect is maintained. However, it is a firm but discriminating "no": clearly (in view of the preceding explanation), it is not the case that "all arguments of the same form can be accepted as valid"; obviously those inadequate applications of the parallel inference as presented by the later Mohist in Situations (2) and (3) are valid because they fail to maintain the minimal consistency and thus the law of identity regarding the same perspective in focus on certain shared (or distinct) attribute in the premise and conclusion statements, as explained before.

In the following illustration (through the "white-horse-is-horse" case versus the "whitehorse-is-not-horse" case ${ }^{13}$ ), I show how the later Mohist semantic sensitivity to due aspects of involved objects can contribute to our understanding and treatment of the deep semanticsyntactic structure of the "parallel-inference" type deductive reasoning.

Now we have two distinct premises:

(1.1) The white horse is (identical to) the horse [regarding the shared "horse-nature" attribute]

Or

$(1.1)^{*}$ The white horse is (identical to) the horse [regarding some attribute that they share] Now we consider

(1.2) The white horse is not (identical to) the horse [regarding the distinct attribute of possessing white color, which is possessed by any white horse but not by all horses]

Or

$(1.2)^{*}$ The white horse is not (identical to) the horse [regarding some distinct attribute that is possessed by any white horse but not by all horses]

Now we can examine the genuine semantic contents of some sample statements as conclusions of the Parallel inference to trace back to their due (relevant and thus adequate) premises.

First consider the following sentence/statement:

(2.1) Selecting the white horse is selecting the horse [with regard to the common 'horsenature' attribute]

Given that (2.1) is a true sentence or is asserted to be true statement and that it is consistently inferred from some premise in some relevant linguistic context, we can reasonably say that it is (1.1) or (1.1)* above, instead of (1.2) or (1.2)*, that constitutes the due premise. (For the sake of

\footnotetext{
${ }^{13}$ For one reason for why these cases are chosen as sample cases, see footnote 10 above. It is also noted that, though the chosen sample examples appear to be simple, it is not implied that the point made through such "simple" sample examples are thus "too simple" to lose its due explanatory force: in philosophical exploration, a sample example chosen for the sake of the reader's understanding and of hitting the point home is not necessarily a complicated one; that is the case for, say, Gongsun Long's "white-horse-not-horse" argumentation.
} 
illustration of such a relevant linguistic context, we can suppose that people hold a "horse" holiday and set out to select a group of horses without regarding their colors; so what is in focus in selecting the white horse and thus referring to the white horse is the "horse-nature" attribute, or some shared attribute, which is possessed by any horse; in this way, selecting the white horse is selecting the horse because the white horse is identical to the horse regarding the "horsenature" attribute or some shared attribute.)

Now consider the following sentence/statement:

(2.2) Selecting the white horse is not (identical to) selecting the horse [regarding the distinct "white-color" attribute which is possessed by any white horse but not by all horses]

Given that (2.2) is a true sentence or is asserted to be true statement and that it is consistently inferred from some premise in some relevant linguistic context, we can reasonably say that it is (1.2) or (1.2)* above, instead of (1.1) or (1.1)*, that constitutes the due premise. (For the sake of illustration of such a relevant linguistic context, we can suppose that people hold a "white-horse" holiday and set out to select a group of white horses regarding their white color; so what is in focus in selecting the white horse and thus referring to the white horse is the "white-color" attribute, or some distinct attribute, which is possessed by any white horse but not by all horses. In this way, selecting the white horse is not identical to selecting the horse because the white horse is not identical to the horse regarding the "white-color" attribute or some distinct attribute that is possessed by any white horse but not by all horses.)

It is noted that the logical "parallel" inference is implemented in a valid way both in the inference from (1.1) to (2.1) and the inference from (1.2) to (2.2). No fallacy, paradox, contradiction or inconsistency is involved in both forms of the parallel inference.

However, unfortunately, those ancient thinkers like the later Mohists in the ancient times did not have due logical resources to formally and accurately present such semantic sensitivity (to the relevant aspects in perspective focus in the parallel inference) and thus reveal the deep semantic-syntactic structure of the parallel inference. This certainly also raises the issue of whether and how contemporary logical resources can formally present the semantic-syntactic structure of the parallel inference and capture the foregoing Mohist point. Indeed, neither the standard predicate logic nor the standard predicate logic with standard form of identity has sufficient logical resources to formally present the foregoing point of the later Mohists' critical examination of various types of application situations of the parallel inference. This does not mean that there is any problem with the parallel deductive reasoning per se but only shows that the standard predicate logic (with identity) has yet to have sufficiently powerful, adequate and sensitive logical resources to formally capture the deductive reasoning in this connection.

\section{The semantic-syntactic structure of the parallel inference via enhanced predicate logic resources}

In this section, to have sufficient logical resources to formally present the foregoing point of the later Mohist diagnose concerning the deep semantic-syntactic structure of the parallel inference, I first propose an account of expanded and strengthened predicate logic and then employ the enhanced logical resources to adequately capture the later Mohist point as explained in the previous section.

\subsection{An expanded predicate logic with enhanced identity sign}


In this sub-section of section 2, I propose the syntax and semantics of an account of expanded and strengthened account of "perspective-sensitive" predicate logic ('PS-PC' for short) with an enhanced identity sign (called "identity with attribute-in-focus parameter", one key element) and many-sorted variable to present the semantic-syntactic structure of the parallel inference. On the one hand, this is what is in need to adequately characterize the semantic-syntactic structure of the parallel inference; on the other hand, in so doing, I explore how the later Mohist resources in this connection can enhance our understanding and treatment of the semantic-syntactic structure of the parallel-inference-type deductive reasoning and contribute to the development of contemporary logical resources.

In this expanded predicate logic account, there are the following additions on the basis of the standard predicate logic, some of which are new or partially new while the others not: (1) adding the sign ' = []' for "aspect-in-focus parameter" identities, which is new; ${ }^{14}(2)$ adding the sign $l^{*}$ for complex noun phrases (definite descriptions), which is a further expansion on the standard $\imath$ operator - semantically defined in a modified way; (3) adding the sign $\lambda$ for complex predicates, which is not new; (4) turning one-sorted logic into many-sorted logic in the way to be defined, which is not new either; (5) this expanded logical system includes both predicate variables and predicate constants (added in our primitive vocabulary) that symbolize attributes; their semantics is partially standard one while being enhanced with modified domain and interpretation, which is partially new. It is tentatively labeled "perspective-sensitive" predicate logic with the "attributein-perspective-focus parameter"'-involved identity (thus 'PS-PC' for short). ${ }^{15}$

\section{(1) Syntax of PS-PC}

\section{(1.1) Primitive vocabulary}

$<1>$ individual variables $x, y \ldots$ with or without numerical or letter subscripts

$<2>$ individual constants (names) $a, b \ldots$, with or without numerical or letter subscripts

$<3>$ sortal variables $s, p \ldots$, with or without numerical or letter subscripts

$<4>$ for each $\mathrm{n}>0$, n-place function symbols $f, g \ldots$, with or without numerical or letter subscript $<5>$ "definite description" symbol $\imath^{* 16}$

$<6>$ for each $\mathrm{n}>0$, n-place predicate variables $X, Y \ldots$, with or without numerical or letter subscripts

$<7>$ for each $\mathrm{n}>0$, n-place predicates (predicate constants) $A, B \ldots$, with or without numerical or letter subscripts

\footnotetext{
${ }^{14}$ When saying that it is new, I mean that the logical notation to be given below, i.e., "the identity symbol with 'perspective-attribute-in-focus' parameter $=$ [ ]", is new, instead of the basic idea of relative identity or its other logical expressions. As emphasized in footnote 10, the basic idea of relative identity can be traced back to Gongsun Long, though he did not use the Chinese counterpart of the very phrase 'relative' identity. Also see the relevant footnote 17 below.

15 The presentations of those added materials that are labeled 'not new' are quite standard; their basic presentation lines and fashions can be found in many textbooks or more advanced source books for classical and non-classical predicate logic, such as Gamut 1991, Priest 2008, and Sider 2010, though newly introduced resources into the system unavoidably bear on some aspects of the presentations of those previous materials.

${ }^{16}$ See its semantic interpretation $(2.2)<1.3>$ below, which distinguishes itself from the standard semantic interpretation of the "definite-description" symbol ' $l$ '.
} 
$<8>$ "identity" symbol with "perspective-attribute-in-focus" parameter $={ }_{[\mathrm{]}}^{17}$

$<9>$ "complex predicate" symbol $\lambda$

$<10>$ connectives: $\rightarrow, \sim$

$<11>$ (universal) quantifier: $\forall$

$<12>$ parentheses: $($, )

\section{(1.2) Definition of terms:}

$<1>$ Any individual variable, sortal variable or individual constant is a term $<2>$ If $f$ is an n-place function symbol and $\alpha_{1} \ldots \alpha_{n}$ are terms, then $f\left(\alpha_{1} \ldots \alpha_{n}\right)$ is a term $<3>$ If $\varphi$ is a formula and $\alpha$ is an (individual or sortal) variable, then $\imath^{*} \alpha \varphi$ is a term $<4>$ Only strings that can be shown to be terms by the preceding clauses are terms

\section{(1.3) Definition of formulas:}

$<1>$ If $\Pi$ is an n-place predicate and $\alpha_{1} \ldots \alpha_{n}$ are terms, then $\Pi \alpha_{1} \ldots \alpha_{n}$ is an (atomic) formula $<2>$ If $\pi$ is an n-place predicate variable and $\alpha_{1} \ldots \alpha_{n}$ are terms, then $\pi \alpha_{1} \ldots \alpha_{n}$ is a formula $<3>$ If $\alpha, \beta$ and $\gamma$ are terms, then $\alpha={ }_{[\gamma]} \beta$ is a formula

$<4>$ If $\varphi$ is a formula, $\alpha$ is a variable and $\beta$ is a term, then $\lambda \alpha \varphi(\beta)$ is a formula $<5>$ If $\varphi$ and $\psi$ are wffs, and $\alpha$ is any variable, then $\sim \varphi,(\varphi \rightarrow \psi)$, and $\forall \alpha \varphi$ are formulas $<6>$ Only strings that can be shown to be formulas using $<1>,<2>,<3>,<4>$ and $<5>$ are formulas

\section{(1.4) Definition of derivative logical symbols:}

$<1>$ Definition of $\wedge$ : " $\varphi \wedge \psi$ " is short for " $\sim(\varphi \rightarrow \sim \psi)$ "

$<2>$ Definition of $\vee$ : " $\varphi \vee \psi$ " is short for " $\sim \varphi \rightarrow \psi$ "

$<3>$ Definition of $\leftrightarrow$ : " $\varphi \leftrightarrow \psi$ " is short for " $(\varphi \rightarrow \psi)$ " $\wedge$ “ $(\psi \rightarrow \varphi)$ "

$<4>$ Definition of $\exists$ : " $\exists \alpha \varphi$ " is short for " $\sim \forall \alpha \sim \varphi$ "

$<5>$ Definition of $\neq:$ " $\alpha \neq{ }_{[\gamma]} \beta$ " is short for " $\sim\left(\alpha={ }_{[\gamma]} \beta\right)$ "

\section{(1.5) Definition of free and bound variables:}

\footnotetext{
${ }^{17}$ For its semantic interpretation, see its semantic interpretation $(2.2)<2.3>$ below, which distinguishes itself from the standard semantic interpretation of the "identity" symbol ' $=$ '. The identity symbol (with the parameter) is a special 2-place predicate constant in nature. It is noted that Geach 1967/1972 presents another logical notation to express relative identity (basically: $x$ and $y$ are the same $F$ but $x$ and $y$ are different $G$ s, where $F$ and $G$ are predicates). (Also see Deutsch 2007.) Generally speaking, I contend that this logical notation in treating relative identity is not merely less natural and expressive (for example, it would be hard to present Gongsun Long's "whitehorse-not-horse" case in terms of Geach's way) but somehow presupposes absolute identity; the suggested identity notation with the parameter as a primitive together with a due semantic interpretation can overcome some difficulties with the former [for example, as indicated in $(2.2)<2.3>$ below, the traditional identity sign expressing absolute identity is treated as one special case, instead of being presupposed]. Specifically speaking, the suggested logical notation of relative identity arguably more fits the deep "parallel" semantic-syntactic structure of the parallel inference under examination.
} 
An occurrence of a variable $\mathrm{x}$ in a formula $\varphi$ is bound in $\varphi$ if and only if that occurrence is in the context of the form $\exists \alpha \varphi$ or $\forall \alpha \varphi$ within $\varphi$. If it is not bound, it is free. A formula with no free variables is a closed formula or sentence; otherwise it is an open formula

\section{(2) Semantics of PS-PC}

Definition of value-assigning interpretation, model, for PS-PC: A PS-PC-model is an ordered pair $\langle D, v\rangle$ such that:

\section{(2.1) $D^{18}$ is a non-empty set ("the domain of quantification"); $D$ is divided into two types of primary subsets as sorts:}

$<1>$ individual-object subsets $O$ of individual objects, $d_{1}, d_{2}, \ldots$, which are divided into various secondary subsets (sorts or sortal collections), $\mathrm{O}_{1}, \mathrm{O}_{2}, \ldots$ whose "nominal" identities (or whose memberships) are given by the distinct term $\imath^{*} \alpha \varphi$ (where $\varphi$ is a formula and $\alpha$ is a sortal variable)

$<2>$ subset $A$ of all specific grounded parts (specific aspects, particular attributes,...) that are grounded in, ${ }^{19}$ and depend on, individual objects (though the defining identities of some of them, such as relational attributes, are grounded in more than one individual objects), which can be further divided into three kinds of subsets whose members can be overlapped:

$<2.1>$ universal-attribute subsets, $A_{1}, A_{2, \ldots}$, which are various subsets of particular attributes whose memberships constitute (or are given respectively by) various universal attributes $<2.2>$ individual-object-association subsets, $A_{d 1}, A_{d 2}, \ldots$, which are different subsets of specific grounded parts (specific aspects, particularly-holding attributes, collectively-holding attributes, generically-holding attributes, ...) whose memberships are given by their respective associations with different individual objects, $d_{1}, d_{2}, \ldots$; each of individual objects $d_{1}, d_{2}, \ldots$, as a whole can be thus labeled $d_{1-A d 1}, d_{2-A d 2}, \ldots{ }^{20}$

$<2.3>$ Among sortal-collection-associated subsets of attributes concerning sortal collections, one type is especially relevant to the current discussion, i.e., the type of sortal-collection-nomimalidentity-contributing subsets which give respectively the nominal identities of distintct sortal collections (i.e., sorts), $\mathrm{O}_{1}, \mathrm{O}_{2}, \ldots$, and which are symbolically labeled by the predicate elements in the "definite description" names (in the form $\imath^{*} \alpha \varphi$ ) of these sortal collections ${ }^{21}$

\footnotetext{
${ }^{18}$ Indeed, a purely-mathematically-oriented logician would render the following characterization of the domain of quantification seemingly too much metaphysically-loaded. It is noted that the primary purpose of presenting this enhanced and expanded predicate logic account is to capture the deep semantic-syntactic structure of the parallel inference for the sake of its validity criterion, instead of merely formal consideration.

${ }^{19}$ There is the discussion over how to characterize the notion of grounding in the literature of contemporary metaphysics. With consideration of the focus of this article, I will not enter into this discussion but presuppose a pretheoretic understanding of it.

${ }^{20}$ Such identities of individual objects with its associated attributes as a whole capture our pre-theoretic understanding of individual objects as "thick" objects, which constitute the semantic-whole referents of the names of such thick objects if they do have names.

${ }^{21}$ Notice that there are other types of sortal-collection-associated subsets, such as the subset of collection-generic attributes and the subset of collection-created attribute, which are not directly relevant to the central topic of this article. I address them in another article on the collective-generic character of common names, which involves a further expanded account of predicate logic on the basis of the suggested expanded account here.
} 


\section{(2.2) $v$ is an (interpretation) function such that:}

\section{$<1>v$ for terms}

$<1.1>$ if $\alpha$ is a (non-predicate) constant, then $v(\alpha) \in D$ :

$<1.1 .1>$ if $\alpha$ is an individual object-identifying constant: $v(\alpha)$ is an individual object in $D$ [which is designated by $\alpha$ ]

$<1.1 .2>$ if $\alpha$ is a particular-attribute-identifying constant: $v(\alpha)$ is a particular attribute $a_{i j}$, which is a member of a "grounded" subset (sort) $A_{i}$ in $A$ (notes: $<\mathrm{i}>$ the subset or the membership of the subset is identified by a "nominal" universal attribute $A_{i}$ that is symbolized by a predicate $P_{i}$, $<\mathrm{ii}>$ the member of the subset is possessed by an individual object in $D$, which is a member of a subset (sort) of D, whose membership is specified and named by a "nominalized" predicate $P_{i}$, i.e., the term $\left.\imath^{*} x P_{i}\right)$

$<1.1 .3>$ if $\alpha$ is a universal-attribute-identifying constant: $v(\mathrm{a})$ is a universal attribute as a universal-attribute subset $A_{i}$ in $A$

$<1.2>$ if $\alpha$ is an individual or sortal variable:

$<1.2 .1>$ if $\alpha$ is an individual variable: $v(\alpha)$ is an individual object in $D$

$<1.2 .2>$ if $\alpha$ is a sortal variable: $v(\alpha)$ is either $<\mathrm{i}>$ an individual object in a subset of $O$, whose membership is specified and named by a "nominal" universal attribute, i.e., the term $l^{*} \alpha \varphi,{ }^{22}$ or $<\mathrm{ii}>$ an (universal) attribute among various universal-attribute subsets, $A_{1}, A_{2, \ldots}$, of $A$ (A as a sort in $D$ ), or $<$ iii $>$ a particular attribute among various members of a universal-attribute subset, $A_{i}$, of $A\left(A_{i}\right.$ as a sort in $\left.A\right)$, or $<$ iv $>$ a particular attribute among various members of an individualobject-association subset, $A_{d i}$, of $A\left(A_{d i}\right.$ as a sort in $\left.A\right)$

$<1.3>$ if $\alpha$ is an $\imath^{*}$ term:

$<1.3 .1>$ if $\varphi$ is a formula and $\alpha$ is an individual variable, then $v\left(l^{*} \alpha \varphi\right)$ is an unique object in $D$ $<1.3 .2>$ if $\varphi$ is a formula and $\alpha$ is a sortal variable, then $v\left(l^{*} \alpha \varphi\right)$ is a (unique) subset (sort) of $D$, which is named, and whose membership is specified, by $\imath^{*} \alpha \varphi^{23}$

$<1.4>$ if $\alpha$ is an n-place function term of the form $f\left(\alpha_{1} \ldots \alpha_{n}\right)$, where $\alpha_{1} \ldots \alpha_{n}$ are terms, and

\footnotetext{
${ }^{22}$ Two samples of their counterparts in natural languages are these: 'the current President of the USA", which as a complex singular term denotes an unique object in $D$, or 'the white horse', which denotes a (unique) subset (sort) of $D$ (all individual white horses). It is noted that, in English, 'the' can indicate one unique object or one unique set/collection/class.

${ }^{23}$ Notice that the semantics for the symbol ' $l$ ' ' is different from the standard one for ' $l$ ' (signifying the uniqueness of the single one object as the referent of a "definite" description) but an enhanced expansion of the latter so as to have it (in the predicate logic) more adequately capture how "definite" descriptions (descriptive noun phrases with unique referents) are used in our linguistic practice (in natural languages): a definite description as a noun phrase denotes either $<1>$ an unique object or $<2>$ a unique set of objects that meet(s) the description of the noun phrase; formally speaking, as indicated in the clause $(2.2)<1.3>$, the semantics for ' $l^{*}$ ' is presented as follows: if $\alpha$ is an $l^{*}$ term: the case $<1>$ is presented this way: if $\varphi$ is a formula and $\alpha$ is an individual variable, then $v\left(l^{*} \alpha \varphi\right)$ is an unique object in the domain $D$, while the case $<2>$ is presented this way: if $\varphi$ is a formula and $\alpha$ is a sortal variable, then $v\left(l^{*} \alpha \varphi\right)$ is a (unique) subset (sort) of $D$, which is named, and whose membership is specified, by $\imath^{*} \alpha \varphi$.
} 
$v\left(\alpha_{1}\right), \ldots v\left(\alpha_{\mathrm{n}}\right)$ are well defined, then $v(\alpha)=v(f)\left[v\left(\alpha_{1}\right) \ldots v\left(\alpha_{\mathrm{n}}\right)\right]$, which is an n-place (total) function on $D$

\section{$<2>v$ for formulas}

$<2.1>$ if $P_{i}$ is an n-place predicate (predicate constant) and $\alpha_{i 1} \ldots \alpha_{i n}$ are terms, then $<\mathrm{i}>v_{o}\left(P_{i}\right)$ concerning individual objects in $D, v_{o}\left(P_{i} \alpha_{i 1} \ldots \alpha_{i n}\right)=1$ iff $\left\langle v\left(\alpha_{i 1}\right) \ldots v\left(\alpha_{i n}\right)\right\rangle \in v_{o}\left(P_{i}\right)$, an nplace relation over $D$, i.e., a subset of n-tuples, individual objects, from $D$, and $<\mathrm{ii}>v_{a}\left(P_{i}\right)$ concerning attributes that are shared by individual objects in $D, v_{a}\left(P_{i}\right)$, is the subset (the universal attribute $A_{i}$ that identifies the membership of the subset) of particular attributes $A_{i 1}, A_{i 2}$ ... which are possessed respectively by these individual objects. [In the following, by default, $v$ $\left(P_{i}\right)$ means $v_{o}\left(P_{i}\right)$ unless indicated otherwise.]

$<2.2>$ if $p$ is a predicate variable

$<2.2 .1>$ if $p$ is an n-place predicate variable and $\alpha_{1} \ldots \alpha_{n}$ are terms, then $v\left(p \alpha_{1} \ldots \alpha_{n}\right)=1$ iff $<$ $\left.v\left(\alpha_{1}\right) \ldots v\left(\alpha_{n}\right)\right\rangle \in v_{\mathrm{o}}(p)$

$<2.2$.2 $>$ if $p$ is a predicate variable and $\varphi$ is a formula, then $v_{o}(\forall p \varphi)=1$ iff for every set of ntuples from $D, v_{o}(\varphi)=1$

$<2.3>$ for any terms $\alpha, \beta$ and for a term $\gamma$ which is either a universal-attribute-identifying constant or a sortal variable ranging over the universal-attribute subsets in $\mathrm{A}, v\left(\alpha{ }_{[\gamma]} \beta\right)=1$ iff $v(\alpha)$ and $v(\beta)$ share $v(\gamma)\left[v\left(\alpha \neq{ }_{[\gamma]} \beta\right)=1\right.$ iff $\left.v\left(\sim\left(\alpha={ }_{[\gamma]} \beta\right)\right)=1\right]$; that is, the formula $\alpha=_{[\gamma]} \beta$ is true iff what the term $\alpha$ denotes is identical to what the term $\beta$ denotes regarding the shared attribute which the term $\gamma$ denotes. Especially, when what the term $\alpha$ denotes is identical to what the term $\beta$ denotes regarding ALL (universal) attributes in A ("absolute identity" for short), the term $\alpha$ and $\beta$ refer to the same object, which case is symbolically labeled ' $\alpha=\beta$ ' [in this way, the traditional identity sign together with its semantic interpretation is one special case of the identity sign with the "aspect-in-focus-parameter"]

It is important to note that, generally speaking, reflexivity does not holds for the "attributeparameter" identity: it is known that identity is a kind of predication; there is no exception that the "attribute-parameter" identity is one kind of predication; given that, semantically, predication is (or belong in) essentially what is said of the subject instead of the reverse, generally speaking, reflexivity should not be, and is not, one intrinsic attribute of predication, and thus, generally speaking, reflexivity should not be one intrinsic attribute of the "attribute-parameter" identity, though it is one attribute of the aforementioned "absolute" identity [i.e., what the term $\alpha$ denotes is identical to what the term $\beta$ denotes regarding ALL (universal) attributes in A, which is labeled ' $\alpha=\beta$ ' as one special case of $\left.\alpha={ }_{[\gamma]} \beta\right]$; the later case holds because, if what the term $\alpha$ denotes is identical to what the term $\beta$ denotes regarding ALL (universal) attributes in A, it is clear that, in this sense and to this extent, what the term $\alpha$ denotes and what the term $\beta$ denotes would be "absolutely" identical to each other and thus that the genuine "reflexivity would occur here: what is said of the subject would be what is said of itself (thus there is no difference between $\alpha=\beta$ and $\beta=\alpha$ ).

$<2.4>$ for any formula $\varphi$, (individual or sortal) variable $\alpha$ and term $\beta, v(\lambda \alpha \varphi(\beta))=1$ iff $v(\beta) \in v(\varphi)$ 
$<2.5>$ for any formulas $\varphi, \psi$, and any variable $\alpha$ :

$$
\begin{aligned}
& v(\varphi \rightarrow \psi)=1 \text { iff either } v(\varphi)=0 \text { or } v(\psi)=1 \\
& v(\sim \varphi)=1 \text { iff } v(\varphi)=0 \\
& v(\forall \alpha \varphi)=1 \text { iff for every } v(\alpha) \in D, v(\varphi)=1
\end{aligned}
$$

It is noted that the inference rules of this expanded account of predicate logic are not given at this point, primarily because the inference rule for the LP deductive inference is what is under examination in the next sub-section. To this extent, the foregoing formal system has yet to be complete; even after the rudimental inference rule for the Parallel inference is given below, a complete account of inference rules involved in the other types of inferences has yet to be given with consideration of the main purpose of this article.

\subsection{A formal presentation of the parallel inference and its inference rule in the expanded account of predicate logic}

In the following illustration (through the white-horse-is-horse case versus the white-horse-is-nothorse case), via relevant logical resources in the foregoing expanded and enhanced account of predicate logic as specified in section 2.1, I show how the later Mohists' semantic truth concern via their adequate sensitivity to due aspects of involved object can contribute to our understanding and treatment of some deep semantic-syntactic structure of the "parallelinference" style deductive reasoning.

\section{Case (1):}

\section{Premise:}

The white horse is the horse [regarding the shared "horse-nature" attribute]

$$
\forall w h \exists h \exists a_{h}\left(l^{*}\left(w h\left[P_{h}(w h)\right]\right)={ }_{\left[a_{h]} l\right.} * h P_{h} h\right)
$$

where ' $w h$ ' and ' $h$ ' are sortal variable that ranges respectively over the white horse (the sort or the sortal collection of individual white horses) and the horse (the sort or the sortal collection of individual horses), ' $a_{h}$ ' is a sortal variable that ranges over the (universal) "horse-nature" attribute (a set of particular "horse-nature" attributes that supervene on particular horses); ' $P_{h}$ ' is a one-place predicate constant whose denotation is a set of individual objects in the domain that possess the "horse-nature" attributes. ${ }^{24}$

\footnotetext{
${ }^{24}$ Notice that, here and below, the semantics for the symbol ' $l$ "' is different from the standard one for ' $l$ ' (signifying the uniqueness of the single one object as the referent of a "definite" description) but an enhanced expansion of the latter so as to have it (in the predicate logic) more adequately capture how "definite" descriptions (descriptive noun phrases with unique referents) are used in our linguistic practice (in natural languages): a definite description as a noun phrase denotes either an unique object or a unique set of objects that meet(s) the description of the noun phrase; formally speaking, as given in Section 3 below, the semantics for ' $l$ ' ${ }^{*}$ is presented as follows: if $\alpha$ is an $l^{*}$ term: $<1>$ if $\varphi$ is a formula and $\alpha$ is an individual variable, then $v\left(l^{*} \alpha \varphi\right)$ is an unique object in the domain $D ;<2>$ if $\varphi$ is a formula and $\alpha$ is a sortal variable, then $v\left({ }^{*} \alpha \varphi\right)$ is a (unique) subset (sort) of $D$, which is named, and whose membership is specified, by $l^{*} \alpha \varphi$. See its semantic interpretation $(2.2)<1.3>$ above.
} 
Or

$(1.1)^{*}$ The white horse is the horse [regarding some attribute that they share]

$$
\forall w h \exists h \exists a_{c} \exists A\left(l^{*} w h A w h={ }_{[} a_{c]} l^{*} h A h\right)
$$

where ' $A$ ' is a predicate variable that ranges over a one-place relation over the domain - a sub-set of 1-tuple in the domain whose sub-set membership is determined by possessing a certain attribute which is shared by the white horse and horse. ' $a_{c}$ ' is a sortal variable that ranges over a certain shared (universal) "common" attribute (a set of particular "common" attributes that are grounded in particular horses).

Actually, when making the parallel inference, one also makes implicit assumption: given that a white horse is to be selected regarding the shared "horse-nature", that is,

$$
\forall w h\left(A_{h} w h \wedge S w h\right)
$$

where ' $w h$ ' is a sortal variable that ranges over the white horse (the sort or the sortal collection of individual white horses), ' $A_{h}$ ' is a one-place predicate constant ("having the horse nature"), and ' $S$ ' is a one-place predicate constant ("being selected").

\section{Conclusion:}

(2.1) Selecting the white horse is selecting the horse [regarding the shared "horse-nature" attribute]

$$
\forall w h \exists h \exists a_{h}\left[l^{*} w h \lambda x\left(A_{h} x \wedge S x\right)(w h)={ }_{[} a_{h]} l^{*} h \lambda x\left(A_{h} x \wedge S x\right)(h)\right]
$$

where ' $\lambda x\left(A_{h} x \wedge S x\right)$ ' is a complex predicate (i.e., a $\lambda$-abstract) which means that 'is such that: it [a white horse or a horse] has the shared "horse-nature" attribute and has the attribute of being selected.

\section{Case (2):}

\section{Premise:}

(1.2) The white horse is not (identical to) the horse [regarding the distinct attribute of possessing white color, which is possessed by any white horse but not by all horses]

$$
\forall w h \exists h \exists a_{w}\left(l^{*} w h A_{w} w h{ }_{[} a_{w]} l * h \sim A_{w} h\right)
$$

where ' $w h$ ' and ' $h$ ' are sortal variable that ranges respectively over the white horse and the horse, ' $a_{w}$ ' is a sortal variable that ranges over the (universal) white attribute (a set of particular white attributes that supervene on particular white things); ' $A_{w}$ ' is a one-place predicate constant whose denotation is a set of individual objects in the domain that possess the white attributes.

Or

$(1.2)^{*}$ The white horse is not (identical to) the horse [regarding a certain distinct attribute that is possessed by any white horse but not by all horses]

$$
\forall w h \exists h \exists a_{d} \exists A\left(l^{*} w h A w h \neq_{[} a_{d]} l^{*} h \sim A h\right)
$$


where ' $A$ ' is a predicate variable that ranges over a one-place relation over the domain - a sub-set of 1-tuple in the domain whose sub-set membership is determined by possessing a certain attribute which is possessed by any white horse but not by all horses; ' $a_{d}$ ' is a sortal variable that ranges over a certain distinct so-and-so (universal) attribute (a set of particular so-and-so attributes that are grounded in particular things that possess the distinct so-and-so attribute).

Similarly in Case (2) to that in Case (1), when making the parallel inference, one also makes an implicit assumption: given that any white horse in the collection of individual white horses is to be selected regarding the distinct "white color", that is,

$\forall w h\left(A_{w} w h \wedge S w h\right)$

where ' $w h$ ' is a sortal variable that ranges over the white horse (the sort or the sortal collection of individual white horses), ' $A_{w}$ ' is a one-place predicate constant ("having the white-color"), and ' $S$ ' is a one-place predicate constant ("being selected").

\section{Conclusion:}

Selecting the white horse is not (identical to) selecting the horse [regarding the distinct "white-color" attribute which is possessed by any white horse but not by all horses]

$\forall w h \exists h \exists a_{w}\left[l^{*} w h \lambda x\left(A_{w} x \wedge S x\right)(w h) \neq\left[a_{w]} l^{*} h \lambda x\left(\sim A_{w} x \wedge S x\right) h\right]\right.$

where ' $\lambda x\left(A_{h} x \wedge S x\right)$ ' is a complex predicate (i.e., a $\lambda$-abstract) which means that 'is such that: it [the white horse] has the distinct "white-color" attribute and has the attribute of being selected.

Now we can answer the title question "How the validity of the parallel inference is possible" in a formal way as follows.

Case (1):

(1a)

Premise: $\quad \alpha={ }_{[\gamma]} \beta$

Premise: $\quad \alpha \varphi \ldots$

Conclusion: $\quad{ }^{*} \alpha \varphi \ldots={ }_{[\gamma]}{ }^{*} \beta \varphi \ldots$

or

(1b)

Premise: $\quad \alpha={ }_{[\gamma]} \beta$

Conclusion: $\quad(\alpha \varphi \ldots) \rightarrow\left(l^{*} \alpha \varphi \ldots={ }_{[\gamma]} l^{*} \beta \varphi \ldots\right)$

and

Case (2): 
$\begin{array}{ll}\text { Premise: } & \alpha \neq{ }_{[\gamma]} \beta \\ \text { Premise: } & \alpha \varphi \ldots \\ \text { Conclusion: } & \imath^{*} \alpha \varphi \ldots \neq_{[\gamma]} l^{*} \beta \varphi \ldots\end{array}$

or

(2b)

Premise: $\quad \alpha \neq{ }_{[\gamma]} \beta$

Conclusion: $\quad(\alpha \varphi \ldots) \rightarrow\left(l^{*} \alpha \varphi \ldots \neq{ }_{[\gamma]} l^{*} \beta \varphi \ldots\right)$

where $\alpha$ and $\beta$ are terms, and $\gamma$ is sortal variable, $\iota^{*} \ldots$ is a term, $\varphi \ldots$ is a formula which might include the negation sign when a sortal variable is involved in Case (2) and whose semantics needs to be consistent with the semantics for $\gamma^{25}$ and $\alpha \neq_{[\gamma]} \beta$ is short for $\sim\left(\alpha=_{[\gamma]} \beta\right)$. I contend that the two presentations of case (1), (1a) and (1b), and the two presentations of case (2), (2a) and $(2 b)$, are semantically and syntactically equivalent.

In this way, a valid parallel inference should maintain the same "perspective-attribute-infocus parameter" identity sign (i.e., focusing on the same aspect of the objects under examination in both premise and conclusion (as one necessary condition for its validity). In view of this, perhaps a more point-capturing label for the parallel-inference type of deductive reasoning is 'perspective-parallel inference', which captures the crucial parallel point to the effect that the same perspective taken to focus on a certain aspect of the object that is formally presented in the enhanced identity sign should be consistently maintained (or in a parallel way) throughout the inference [both in its premise(s) and in its conclusion].

What is given above is still a formal outline to capture the basic schematic semantic-syntactic structure that shows how the foregoing semantic sensitivity can, and needs to, be formally turned into a syntactic-logical formulation for the sake of giving a general condition for the validity of the parallel inference. A completed account of formal details can be further implemented in the direction of the foregoing schematic formulations.

\section{Concluding remarks}

In sum, my views are these. First, the later Mohists as presented in the $X Q$ and other texts of the Mohist Canons were highly sensitive to the refined semantic relation between language expressions and the way things are (thus a semantic-truth concern) in the predicative context of saying something about objects (as referents of names); the later Mohists implemented this semantic sensitivity in their reflective examination of the parallel inference; such a semantictruth concern in the later Mohist logical discourse motivated the later Mohists to alert us to meet certain adequate conditions for validly carrying out the parallel inference. Second, on the other hand, the later Mohists then did not have due resources to formulate the general inference rule for the validity of the parallel inference in an effective and unified way for the sake of guaranteeing its adequate applications (in the case of “是而然”, explicitly addressed, and of “不 是而不然”, implicitly addressed) while against introducing inadequate (i.e., contextually irrelevant) premises (in the cases of “是而不然” and “不是而然”); this has partially brought about, or at least contributed to the subsequent misunderstanding and mistreatment of the status

${ }^{25}$ This restriction is given for the sake of avoiding the case in which $\varphi \ldots$ is assigned a value that is inconsistent with, or contradictory to, the value assigned to $\gamma$. 
and nature of the parallel inference. Third, however, with the enhanced predicate logic resources as suggested in this paper, the deep semantic-syntactic structure of the parallel inference (or more adequately labeled 'perspective-parallel inference' or 'perspective-parallel-type' deductive reasoning) can be captured and presented in a formal way, although both ancient logical resources during the later Mohist times and the so-far-available logical resources (including currently available expanded predicate logic accounts) have yet to be refined enough to take on, or are unable to formally apprehend, this.

A significant relevance of this discussion to a more general concern, to whose scholarship this discussion is also intended to contribute, is this. For the sake of giving a refined consideration of the validity of a deductive reasoning that involves saying something about an object (objects) under examination, this discussion addresses the need for maintaining due semantic sensitivity to which aspect of the object(s) would be in perspective focus in such a reasoning; this discussion suggests one way to meet the need through explicitly introducing some logical resources that are sensitive to the addressed semantic sensitivity (such as the enhanced identity symbol with the "aspect-in-perspective-focus" parameter in an expanded predicate logical account).

\section{Acknowledgments}

Early versions of (Section 1 of) this paper were presented respectively at 2014 term of "Beijing Roundtable on Contemporary Philosophy" Workshop Series [organized by the International Society for Comparative Studies of Chinese and Western Philosophy (ISCWP) and co-sponsored by Institute of Foreign Philosophy \& Center for Analytic Philosophy, Peking University, China (Host) and Center for Comparative Philosophy, San Jose State University] on "Mohist Logical Thought and Development of Contemporary Philosophy" (7 June 2014, Beijing, China) and at 2015 term of the SJSU Center for Comparative Philosophy's Workshop/Conference Series (2 May 2015, San Jose, USA) at which Linhe Han, Chung-I Lin, Xinwen Liu, Jeremy Seligman, Richard Tieszen, Anand Vaidya, Marshall Willman and Taotao Xing gave thought-stimulating critical comments for which I am grateful to them. Thanks to Yiu-ming Fung, Xiaojun Ding and Hongyin Zhou for their helpful feedback to an early draft of the full text of this paper. I am grateful to one anonymous referee at this Journal for his/her detailed comments and suggestions that strengthened the paper.

\section{References}

Deutsch, H. 2007. 'Relative Identity', in Stanford Encyclopedia of Philosophy [http://plato. stanford.edu/entries/identity-relative/]

Fung, Y. 2012. 'A Logical Perspective on the Parallelism in Later Moism', Journal of Chinese Philosophy, 39, 333-350.

Fraser, C. 2013. 'Mohist Canons', in Stanford Encyclopedia of Philosophy [http://plato.stanford. edu/entries/mohist-canons/]

Gamut, L.T.F. 1991. Logic, Language, and Meaning (2 vols.), Chicago and London: The University of Chicago Press.

Geach, P. T. 1967. 'Identity', Review of Metaphysics, 21, 2-12. Reprint in Greach 1972, 238-247.

Geach, P. T. 1972. Logic Matter, Oxford: Blackwell. 
Graham, A.C. 1967. 'History of Logic', in P. Edwards (ed.), The Encyclopedia of Philosophy, volume IV, New York: Macmillian.

Graham, A.C. 1978/2003. Later Mohist Logic: Ethics and Science (1978 first edition / 2003 reprint edition), Hong Kong: Chinese University Press.

Hansen, C. 1983. Language and Logic in Ancient China, Ann Arbor, MI: University of Michigan Press.

Johnson, I. trans. 2010. The Mozi: A Comparalleleted Translation, New York: Columbia University Press.

Liu, P. 劉培育 2004. 'Zhong-Guo-Ming-Bian-Xue' '中國名辯學' [Chinese Studies of Names and Augumentation], Part I of Zhang, J. 張家龍 (ed.) 2004. Luo-Ji-Xue-Xi-Xiang-Shi《逻辑 学思想史》[History of Logical Thoughts], Changsha: Hunan Education Press 湖南教育出 版社, 1-158.

Mou, B. 2006. 'Chinese Philosophy: Language and Logic', in D. M. Borchert (ed.), Encyclopedia of Philosophy (second edition), Chicago, IL: Thomson-Gale/Macmillan Reference USA, 202-215.

Mou, B. 2007. 'A Double-Reference Account: Gongsun Long's "White-Horse-Not-Horse" Thesis', The Journal of Chinese Philosophy, 34, 493-513.

Mou, B. 2009. 'On Some Methodological Issues Concerning Chinese Philosophy', in B. Mou (ed.), History of Chinese Philosophy, London and New York: Routledge, 1-39.

Priest, G. 2008. An Introduction to Non-Classical Logic, Cambridge University Press.

Robin, D. 2010. 'The Later Mohists and Logic', History and Philosophy of Logic, 31, 247-285.

Sider, T. 2010. Logic for Philosophy, Oxford: Oxford University Press.

Willman, D. 2010. 'Logical Analysis and Later Mohist Logic: Some Comparative Reflections', Comparative Philosophy, 1, 53-77 <http://www.comparative philosophy.org >.

$\mathrm{Wu}, \mathrm{Y}$. 吳毓江(ed.). 2006. Mo-Zi-Jiao-Zhu《墨子校注》[The Mo-Zi Text with Annotations], in Xin-Bian-Zhu-Zi-Ji-Cheng (Di-Yi-Ji)《新編諸子集成》(第一輯), Beijing: Zhong-Hua-Shu$J u$ 中華書局. 